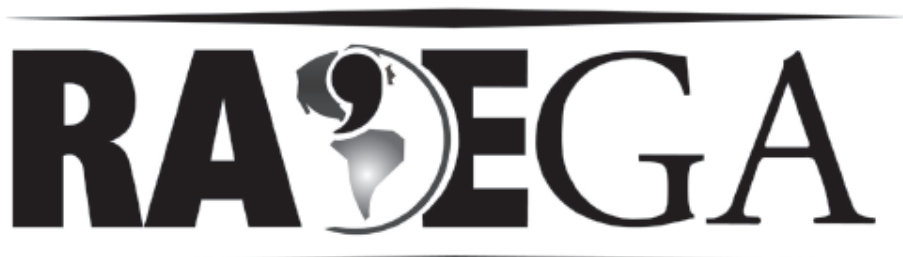

O ESPAÇO GEOGRÁFICO EM ANÁLISE

\title{
DIFUSÃO DA INOVAÇÃO, CONSUMO E COTIDIANO NO CAMPO MODERNO - NOTAS SOBRE O PAPEL DAS FEIRAS AGROPECUÁRIAS EM RONDÔNIA (BRASIL)
}

\section{INNOVATION'S DIFFUSION, CONSUMPTION AND EVERYDAY IN THE MODERN FIELD - NOTES ABOUT THE ROLE OF AGRICULTURAL EVENTS IN RONDÔNIA (BRAZIL)}

\author{
Mirlei Fachini Vicente Pereira ${ }^{1}$
}

\section{Resumo:}

O texto avalia a função das feiras e eventos agropecuários no processo de modernização das atividades agrícolas no estado de Rondônia, especialmente nas áreas onde recentemente o campo se torna mais denso em técnica e voltado para as estruturas corporativas de produção. Discuti-se 0 papel que tais eventos possuem na disseminação da ciência e da informação voltadas para as inovações produtivas no campo, inserindo novas necessidades de consumo e um efeito de modernização no território.

Palavras-chave: Informação, inovação, consumo produtivo, eventos agropecuários, "psicosfera".

\section{Abstract:}

The article evaluate the role of agricultural events in the process of modernization agricultural activities in Rondônia state (Brazil), especially in areas where recently the field becomes more dense in technical and geared to modern production of great companies. It was discussed the role these

\footnotetext{
${ }^{1}$ Professor Adjunto, Instituto de Geografia. Universidade Federal de Uberlândia. mirlei@ig.ufu.br
} 
agricultural events for the dissemination of science and information directed to the productive innovations in the field, introducing new requirements for consumption and one modernizing effect in territory.

Key-words: information, innovation, productive consumption, agricultural events, "psychosphere".

\section{Introdução: Agricultura em Rondônia e a modernização recente do campo}

No período atual o Brasil conhece uma renovação de infra-estruturas territoriais e atividades produtivas que oportuniza a expansão das atividades agrícolas modernas em espaços que, até pouco tempo, eram muito caracterizados por uma agricultura pouco moderna e voltada para as demandas internas. O estado de Rondônia conhece esta modernização recente da produção agrícola, e insere a Amazônia brasileira entre os novos espaços da produção agrícola globalizada.

A área que hoje compõe o estado de Rondônia, na região Norte do Brasil (Figura 1), tem sua história muito ligada ao uso agrícola do território, iniciado nas décadas de sessenta e setenta do século XX por milhares de migrantes camponeses que vieram ocupar e trabalhar terras devolutas (originalmente ocupadas por indígenas de diferentes etnias).

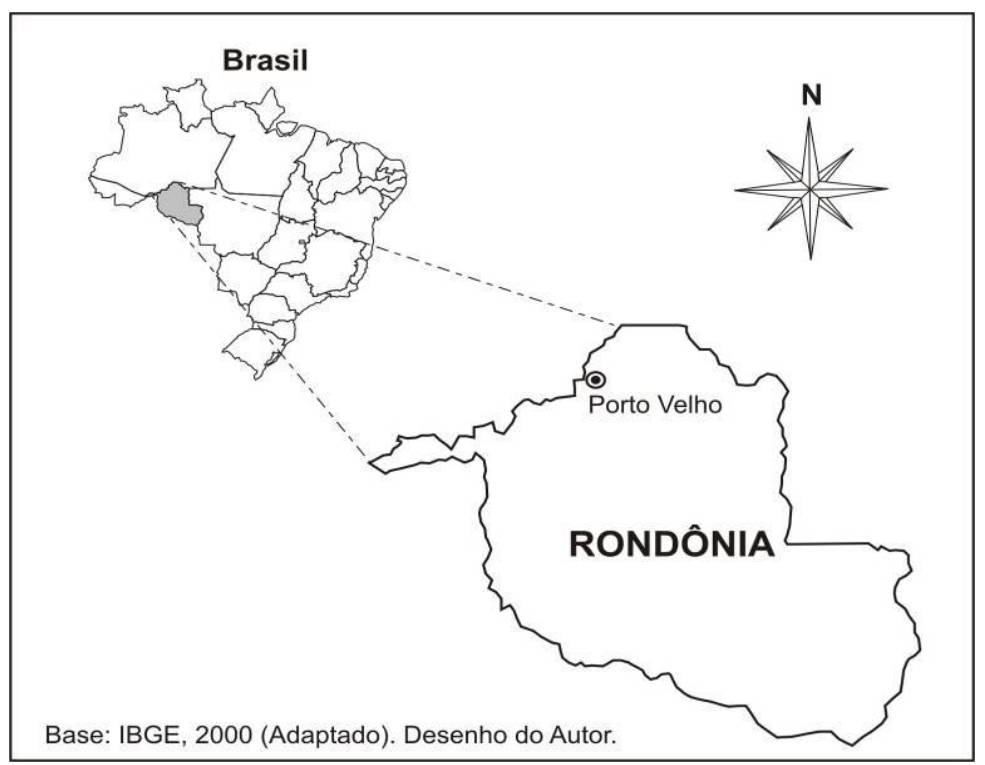

Figura 1. Localização do Estado de Rondônia, Brasil. 
A partir dos anos 70, tal processo de ocupação se intensifica, acompanhado por políticas públicas que incentivam um acelerado ritmo de ocupação territorial, concomitantemente à criação de um conjunto de novos municípios (no ano de 1977). Recebendo produtores agrícolas (capitalizados e não capitalizados) de diferentes estados do Centro-Sul do país (sobretudo paranaenses, gaúchos e paulistas), o então Território Federal do Guaporé torna-se nova unidade da federação no ano de 1988, recebendo a denominação Rondônia, homenagem ao Marechal Candido Rondon, que no início do século desbravara as terras que hoje compõem o estado.

Também a partir da década de setenta esta porção do país recebe um conjunto de novos agentes que inserem na região atividades que aparecem como mais lucrativas e voltadas aos interesses do governo militar, como é o caso da mineração (sobretudo para a produção de estanho) e também a pecuária extensiva, atividade esta que concorre diretamente com a agricultura camponesa e muitas vezes ocupa espaços originalmente destinados aos cultivos agrícolas que há pouco tempo haviam sido implantados por camponeses pouco capitalizados. Enfrentando disputas por terra resultantes de conflitos entre diferentes interesses de uso do território, o meio geográfico e a estrutura fundiária da região conhecem, nos anos 70 e 80 , certa preparação para a empresa capitalista de origem externa.

No entanto, uma verdadeira reestruturação territorial e produtiva ocorrerá apenas na década de noventa, quando grandes grupos econômicos visualizam nas possibilidades oferecidas pelo meio geográfico novas oportunidades de uso do território e de acumulação. Durante os 70 e 80 os cerrados do Brasil central foram largamente ocupados por uma agricultura moderna e que tinha como meta a produção de exportação em larga escala, amplamente mecanizada e com uso intensivo de insumos químicos (fertilizantes e agrotóxicos). No entanto, e como esta agricultura de exportação é exigente de uma logística que possa tornar competitivo o produto no mercado externo (CASTILLO, 2005), havia a necessidade de se pensar estratégias de circulação e escoamento da produção realizada no interior do país, e logo quando se adensam os cultivos no oeste do Mato Grosso (Chapada dos 
Parecis), o grupo mato-grossense André Maggi intenciona realizar 0 escoamento de grãos pelas águas dos rios Madeira e Amazonas, diminuindo os custos com o transporte da produção que até então era feita através dos portos do Sudeste e Sul do país.

Fazendo das necessidades corporativas do agronegócio uma verdadeira demanda do território e da região, o governo federal (primeiro governo de Fernando Henrique Cardoso) e os governos estaduais de Rondônia e Amazonas viabilizam o projeto da hidrovia Madeira-Amazonas. A partir do ano de 1998, são iniciadas as operações de escoamento de grãos pelo rio Madeira, com a instalação em Porto Velho de um terminal privativo da Hermasa, empresa de propriedade do Grupo André Maggi, inaugurando um novo corredor de exportação de grãos na região Norte do país.

A concretização da hidrovia foi de extrema importância para o incremento de novas atividades produtivas e na reestruturação das atividades agrícolas no estado de Rondônia, visto que o território passa a ser mais competitivo no que diz respeito à produção de exportação. Assim, com o novo corredor de exportação do Madeira-Amazonas, a produção de grãos se torna viável também em Rondônia, oportunizando o avanço sobretudo do cultivo da soja na porção sul do território, onde as condições naturais favoráveis passam a ser efetivamente (e intensivamente) exploradas.

Para se ter uma melhor idéia deste processo, ainda que a produção de soja no estado de Rondônia seja pouco expressiva quando comparada ao total do país, a área plantada no território rondoniense cresceu cerca de sete vezes entre os anos de 1995 e 2005, enquanto que, no mesmo período, a quantidade produzida aumentou mais de vinte vezes, dados estes que, pelo expressivo aumento da produção e da produtividade, atestam a inserção de uma agricultura moderna no estado ${ }^{2}$. Grandes grupos voltados para o cultivo de commodities valorizadas no mercado externo (André Maggi, Cargill, entre outros) passam a atuar e coordenar a produção agrícola de exportação

\footnotetext{
${ }^{2}$ Dados divulgados pela SEAPES - Secretaria de Estado da Agricultura, Produção e Desenvolvimento Econômico e Social de Rondônia. Disponível em www.seapes.ro.gov.br/Boletins/bol 06 05/sumario.htm , acesso em 11/2005.
} 
(sobretudo a soja), reestruturando as atividades produtivas no campo rondoniense.

Na agricultura, a inserção de insumos e o uso de técnicas modernas são responsáveis pelo constante crescimento e modernização da produção no campo. O emprego racional de fertilizantes, a gestão em tempo real das informações necessárias ao trabalho de adubação dos solos e da atividade de plantio são alguns exemplos da tecnologia empregada no agronegócio da soja em Rondônia.

$\mathrm{Na}$ pecuária, um processo de recente de aplicação da ciência na produção, marcado pelo crescente emprego das técnicas modernas de inseminação artificial, melhoramento genético e manejo adequado de pastagens, somado a um conjunto de normas territoriais (incentivos fiscais) que garantem competitividade às atividades de industrialização da produção (agora também comandada por grupos estrangeiros), tornam o estado de Rondônia extremamente competitivo no que diz respeito à produção de carne bovina, conferindo recentemente um aumento extraordinário do abate de animais, tornando o estado o quinto maior produtor de carne do Brasil, produto este que inclusive é destinado ao mercado externo ${ }^{3}$.

O uso intenso da técnica, da ciência e da informação, muito presentes nos maquinários agrícolas sofisticados, nas sementes melhoradas e nos fertilizantes, nas técnicas sofisticadas do melhoramento genético vegetal e animal, exemplifica a natureza técnico-científica da produção, permitindo reconhecermos a consolidação de áreas cada vez maiores no Brasil em que o meio técnico-científico-informacional (SANTOS, 1994a, 1996) se faz presente para atender às demandas de uma agropecuária científica e globalizada.

Toda esta modernização das atividades produtivas no campo é muito exigente de informação. As inovações científicas e tecnológicas constituem elemento central ao processo de produção voltada para a acumulação de grandes agentes que, no mais das vezes, trabalham em função de interesses externos. Uma série de modernidades voltadas para esta produção pode

\footnotetext{
${ }^{3}$ No ano de 2007, o estado de Rondônia alcança a 5a colocação entre os maiores estados produtores de carne bovina no Brasil (no ano 2000, Rondônia ocupava a 10 posição). Ao mesmo tempo, Rondônia também se torna o quinto maior estado exportador de carne do país (ABRAFRIGO, 2008).
} 
facilmente ser observada num conjunto, cada vez mais crescente, de feiras e eventos agropecuários que são realizados anualmente nas cidades em que a produção agropecuária aparece com maior força no estado de Rondônia.

Tal como aponta Denise Elias (1998), na análise do campo moderno, as feiras e eventos associados à produção agropecuária constituem um importante recurso de pesquisa, visto que se pode observar nestes eventos os principais tipos de produtos e serviços comercializados, as inovações tecnológicas, a origem das empresas expositoras, entre outras informações (ELIAS, 1998, p.106) que oportunizam a compreensão da dinâmica do território em áreas do campo moderno ou em processo de modernização.

Em Rondônia, estas feiras e eventos agropecuários, para além de difundirem as modernidades no campo, também são muito responsáveis pela veiculação da idéia de modernização necessária da produção. Uma verdadeira "psicosfera" modernizadora (SANTOS, 1996) acaba por incentivar as práticas que, de modo geral, legitimam a inserção de uma racionalidade mercadológica da produção agropecuária, processo este que é cada vez mais regido por grandes grupos econômicos que coordenam a produção agrícola e pecuária modernas. Em outras palavras, "Essa racionalidade se traduz na produção agrícola por políticas que favoreceram superposições de tecnologias, derivadas sobretudo de pesquisas científicas e inovações na gestão e no controle da produção sob o comando de grandes empresas" (RAMOS, 2001, p.375).

Assim, o objetivo deste ensaio é avaliar o fenômeno das feiras e eventos agropecuários no estado de Rondônia, visando elucidar o papel dos mesmos para a difusão da informação e de suporte para um consumo produtivo do campo e mesmo para a afirmação de um cotidiano do campo moderno que condiciona ações e comportamentos, elementos esses essenciais ao processo de modernização/racionalização do campo no território rondoniense. 


\section{Feiras e eventos agropecuários no estado de Rondônia}

Presente nos insumos, nas máquinas e mesmo na produção propriamente dita, a informação especializada aparece como variável fundamental do período, indispensável às práticas da agricultura e da pecuária modernas. No estado de Rondônia, especialmente nos espaços da produção moderna, o acesso à informação e também a difusão das inovações no campo (novas tecnologias e tudo aquilo que aparece como modernidade), se dão muito em função da realização de feiras e exposições agropecuárias, que hoje ocorrem em mais da metade dos municípios de Rondônia.

No ano de 2007, o cadastro do governo do estado e da Superintendência Federal de Agricultura de Rondônia (SFA-RO) contabilizava dezenove eventos relacionados às atividades agropecuárias, eventos estes realizados nos principais municípios produtores (SEAPES, 2007). No entanto, eventos menores ou de realização ainda recente e que não possuem apoio de instituições governamentais também são realizados no estado (Figura 2).

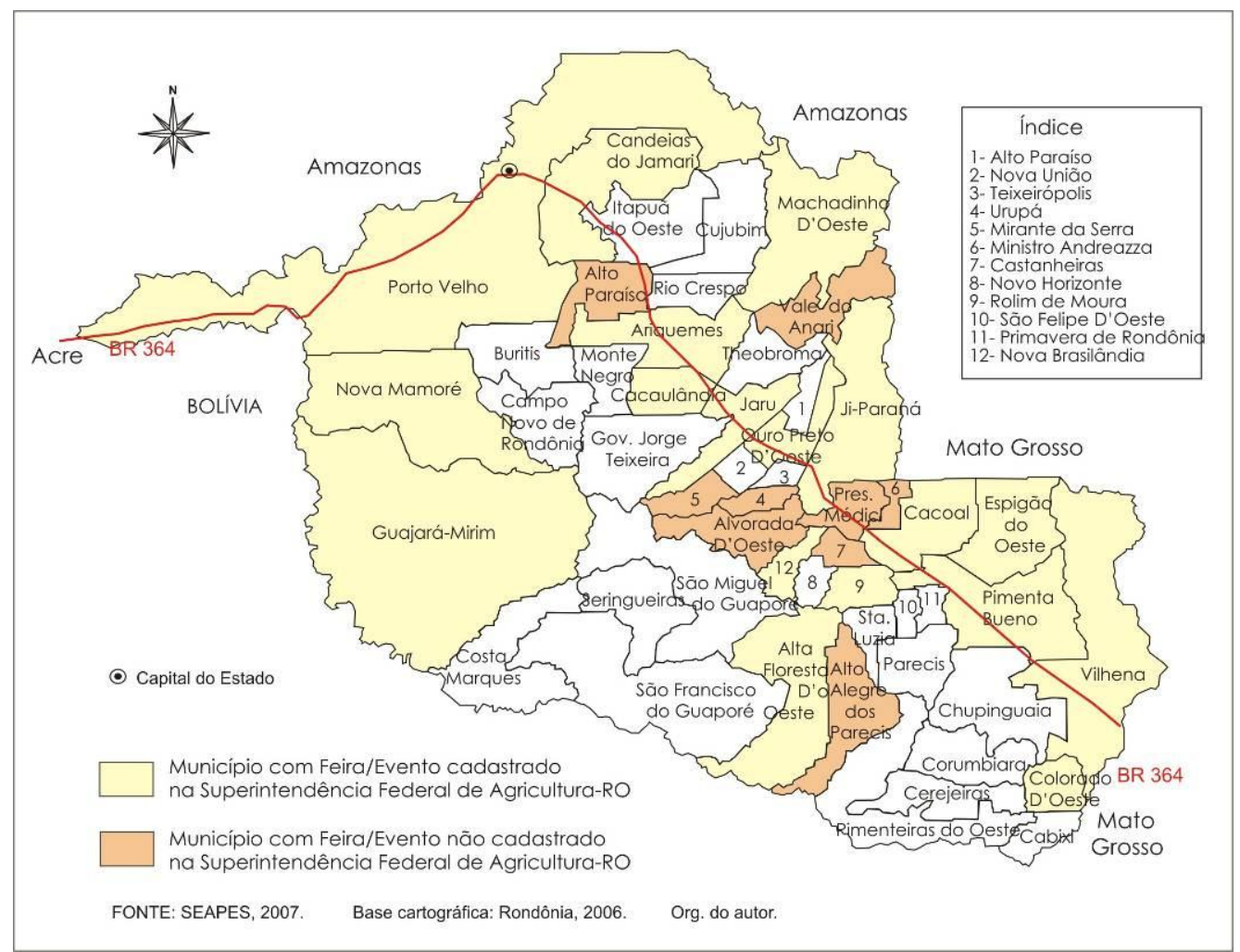

Figura 2. Feiras e eventos agropecuários no Estado de Rondônia (2007) 
A Exposição Agropecuária de Vilhena (Expovil) é um dos mais tradicionais eventos do setor agropecuário no estado de Rondônia, realizada há mais de vinte anos. O evento, que ocorre normalmente no mês de julho, é realizado num recinto de exposições de propriedade da AVIAGRO Associação Vilhenense de Agropecuária. Acompanhando a lógica da especialização produtiva, as atividades de maior importância da feira são justamente aquelas ligadas à agricultura da soja e também à criação de bovinos de corte (Figura 3).
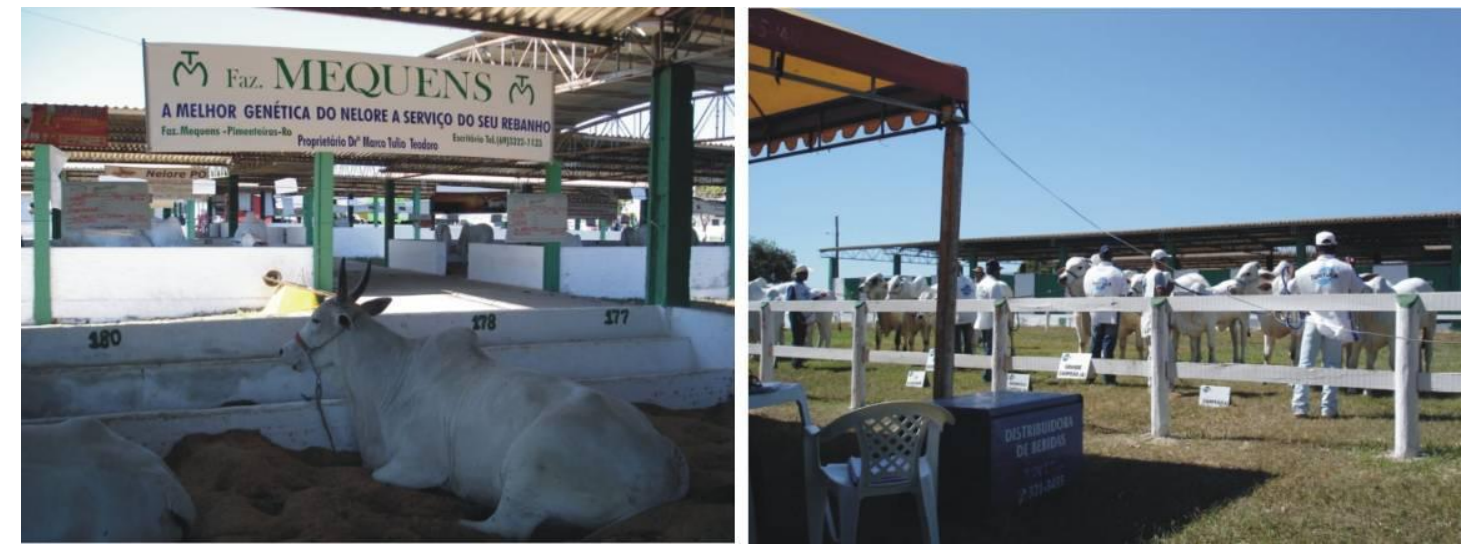

Figura 3. Exposição de animais, Expovil 2007, Vilhena-RO. Exposição de gado nelore (na faixa menção ao melhoramento genético em fazenda de Pimenteiras-RO (esquerda) e concurso estadual de animais (direta) (Fotos do autor, julho de 2007).

No município de Vilhena, todo o potencial de uma agricultura científica, típica deste período de globalização, é empregado nas atividades produtivas do campo. Maquinários dos mais modernos do mundo realizam o trabalho a partir de um comando que é operado por satélites (através de aparelhos de GPS) que produzem, instantaneamente, diagnósticos de produtividade e cálculo da quantidade necessária de corretivos a ser adicionado ao solo, otimizando o uso de insumos, fertilizantes e venenos, verificando ainda o controle dos espaçamentos e da profundidade das covas para o plantio das sementes, com uma margem de erro de apenas 10 centímetros, configurando um tipo de cultivo comumente caracterizado como "agricultura de precisão" ${ }^{4}$. Tais produtos

\footnotetext{
${ }^{4}$ Produtores de soja em Vilhena são citados em matéria publicada em uma Edição Especial sobre Agronegócio da Revista Veja, em abril de 2004, onde se destacou o emprego da "agricultura de precisão"
} 
e inovações são divulgados e podem ser adquiridos neste tipo de evento, que desta forma desempenha importante papel no que tange ao consumo produtivo do campo (ELIAS, 2003, p.191, 2006).

Como tal consumo produtivo é também exigente de grande capital, pode-se tomar empréstimos em bancos públicos ou instituições privadas no mesmo espaço das feiras. Para se ter uma idéia da importância econômica destes eventos, em 2007, o escritório do Banco da Amazônia (BASA) instalado no recinto de exposições da Expovil recebeu, somente durante a semana de realização do evento, propostas de contratação de crédito para compras de maquinários que totalizaram aproximadamente $R \$ 20$ milhões. No mesmo ano, nas exposições agropecuárias realizadas nos municípios de Colorado do Oeste (XXI Expocol) e de Cerejeiras (1 $1^{\text {a }}$ Expocer), o valor das propostas para contratação de crédito alcançou, aproximadamente, $R \$ 3$ milhões e $R \$ 2$ milhões, respectivamente ${ }^{5}$. Tais informações nos autorizam pensar que a difusão da inovação no campo moderno também carece, necessariamente, também de uma difusão do crédito.

A exposição de Vilhena conta com apoio de deputados estaduais e com o patrocínio das principais empresas que vendem maquinários, insumos e fornecem assistência técnica para o plantio e colheita de grãos (Figura 4). São, assim, políticos, instituições ou associações de produtores e os agentes hegemônicos do campo moderno (no mais das vezes empresas de capital estrangeiro) os principais fomentadores destas feiras e exposições voltadas para a produção agrícola intensa em capital e em informação.

no município. "O agricultor gaúcho Adailton Sawaris e seu sócio, o paranaense Nivaldo dos Santos, ambos de 35 anos, conseguem bater recordes de produtividade no município de Vilhena, em Rondônia, com a utilização destas técnicas. A cada safra, eles fazem um histórico com vinte variáveis - como acidez do solo e índice pluviométrico - de cada um dos cinqüenta trechos, ou talhões, em que estão divididos 5 600 hectares da plantação de soja. Por meio de um aparelho que localiza coordenadas geográficas com o auxílio de satélites, otimizaram a aplicação de insumos e a pulverização da lavoura, evitando a sobreposição. 'O plantio é feito com controle automático dos espaçamentos, da profundidade das covas e da quantidade de adubo aplicado', explica o especialista José Molin, professor da Escola Superior de Agricultura Luiz de Queiroz da Universidade de São Paulo. 'As super-máquinas reduzem significativamente os custos da produção'”. (COUTINHO, 2004, p.27).

\footnotetext{
${ }^{5}$ Informações obtidas junto à gerência do BASA, agência de Vilhena, em trabalho de campo realizado em
} julho de 2007. 


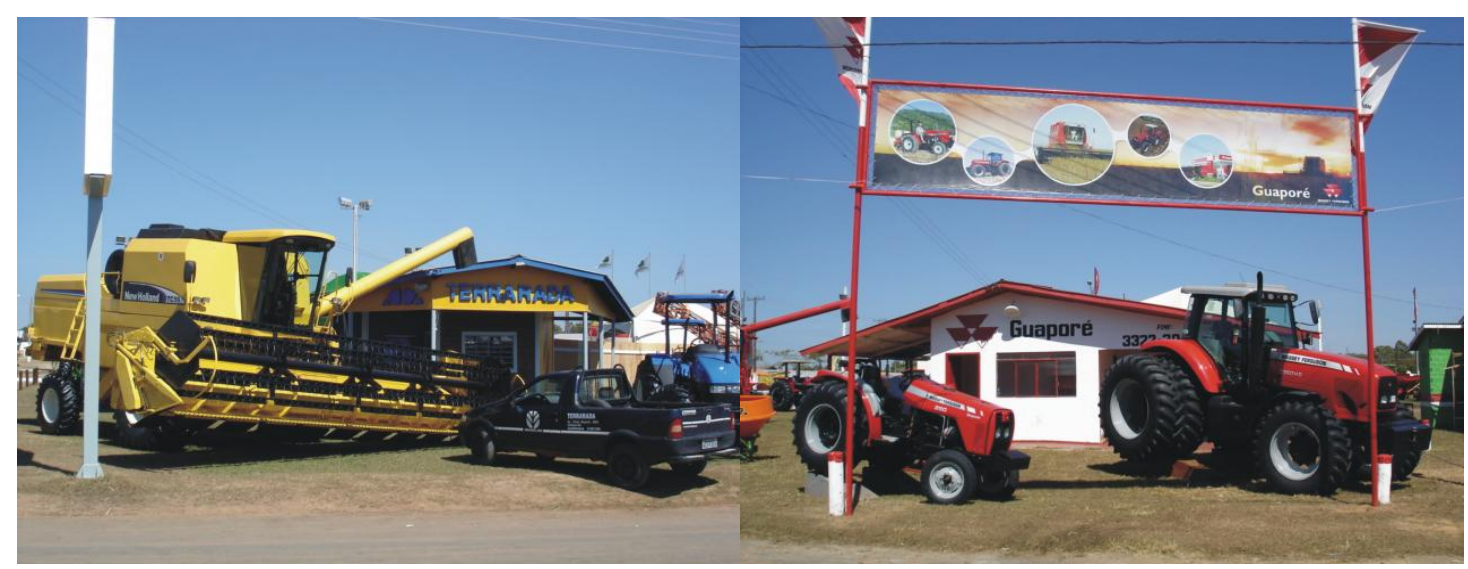

Figura 4. Máquinas agrícolas expostas na Expovil 2007, Vilhena-RO. A Exposição tem como uma de suas principais funções a difusão de novidades tecnológicas do setor. Colheitadeira de grãos (à esquerda). Tratores (à direita). (Fotos do autor, julho de 2007).

A idéia de campo moderno está muito presente em boa parte do espaço urbano. Em Vilhena, as ruas e avenidas largas estão repletas de grandes caminhonetes (em boa parte importadas). É nítida a presença de novos prédios comerciais, vários deles ainda em construção (a maioria com anúncio de financiamento do Banco da Amazônia S.A.). O cotidiano urbano, sobretudo daqueles agentes e ações solidários e obedientes à agricultura moderna, parece a todo tempo estar sendo gerenciado por esta mesma racionalidade de modernização. É assim que esta idéia de campo moderno se dissemina e se legitima entre agentes que participam direta e indiretamente das atividades agropecuárias modernas e capitalizadas, e de certo modo também entre aqueles que não participam de forma vantajosa dos circuitos produtivos típicos do campo modernizado.

Difundindo a informação e participando diretamente do consumo produtivo do campo, as cidades e a feiras agropecuárias também são difusoras, deste modo, de uma "psicosfera modernizadora" (SANTOS, 1994a, 
p.32; 1996, p.204), muito presente no período das feiras na maior parte dos veículos locais de comunicação, que garante legitimidade às ações públicas e privadas que organizam a produção moderna no campo, construindo no imaginário social uma idéia de progresso e de modernização. Nas palavras de Santos e Silveira,

\begin{abstract}
É sobretudo esse crescente consumo de informação que participa do alastramento de uma psicosfera modernizadora, impondo racionalidades mas também despertando ou fabricando um imaginário. Ambas, tecnosfera e psicosfera, formas de existência do meio técnico-científico-informacional, condicionam os comportamentos e entretecem racionalidades e emoções convergentes e conflitantes (SANTOS; SILVEIRA, 2001).
\end{abstract}

Em Ji-paraná, tal situação de certo modo se repete. Vitrine para a exposição principalmente de gado, a Expojipa (que é realizada em Ji-paraná desde 1980) se consolida como o maior evento agropecuário de Rondônia.

A infra-estrutura do parque de exposições de Ji-paraná é melhor e mais equipada quando comparada àquelas do parque de exposição de Vilhena e também aos de Colorado do Oeste e Cerejeiras. Praças e jardins bem estruturados ornamentam o recinto de exposições que conta com construções em alvenaria que abrigam bancos e empresas. Organizada pela Associação Rural do Estado de Rondônia, a Expojipa é provavelmente a maior feira/exposição agropecuária de toda a Região Norte do país, recebendo em 2006 um público de mais de 250 mil pessoas (Figura 5) ${ }^{6}$.

\footnotetext{
${ }^{6}$ Vide reportagem de J. Coelho (2007), no Jornal Folha de Rondônia (em 22 de maio de 2007).
} 

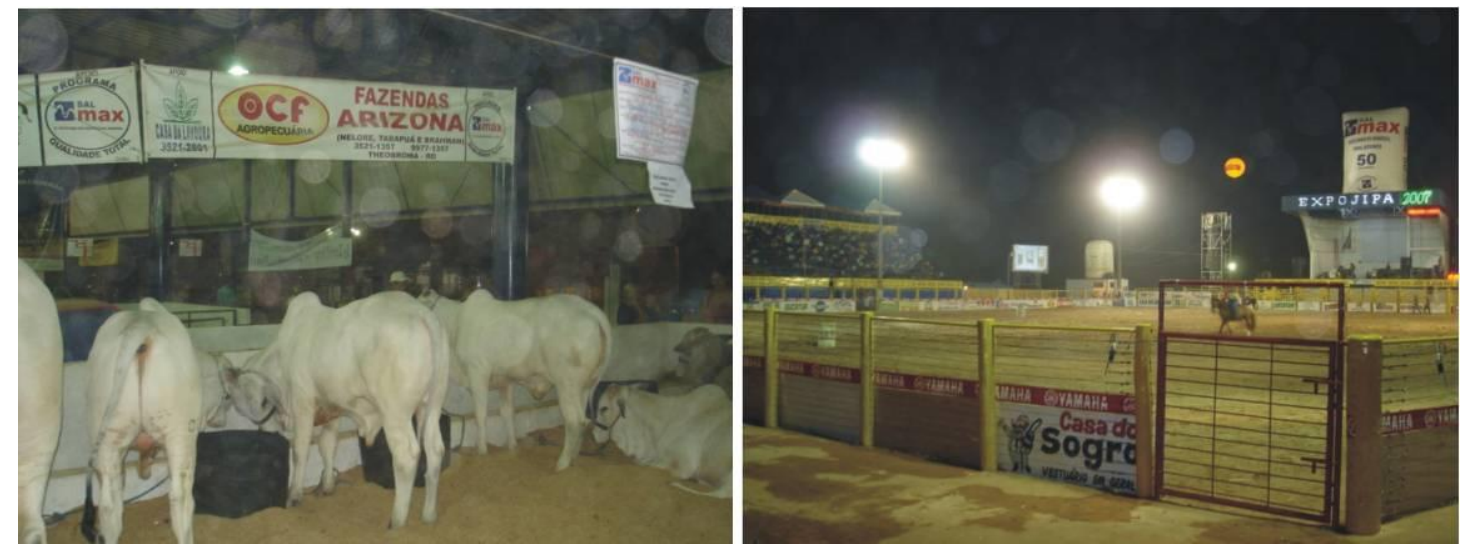

Figura 5. Expojipa 2007, Ji-paraná-RO. Em Ji-paraná, que detém o terceiro maior rebanho bovino de corte em Rondônia, a Expo-Jipa é o principal evento do setor agropecuário. Exposição de gado nelore (à esquerda). Arena de rodeio e palco de apresentações musicais (à direita). (Fotos do autor, julho de 2007).

Como Ji-paraná se afirma como um dos principais municípios produtores de leite de Rondônia, o evento conta com concursos e exposição de exemplares bovinos de várias partes do estado e do país, bem como para os recursos técnicos de inseminação artificial e melhoramento genético de animais, além da divulgação e venda de equipamentos para o beneficiamento de leite.

Os espaços e infra-estruturas utilizados para a realização de tais eventos aparecem, assim, como equipamento urbano indispensável, sendo estes mais estruturados nas cidades onde se praticam atividades agropecuárias modernas. Os chamados "parques" ou "recintos de exposição" existem em muitas cidades de Rondônia com diferentes configurações, espaços estes que são, na maioria dos casos, organizados por sindicatos ou associações de produtores rurais.

Para além da importância econômica e estratégica na difusão das modernidades no campo, estas feiras e eventos agropecuários acabam se tornando verdadeiros "acontecimentos do ano" em algumas cidades, o principal ou mesmo único momento de diversão e de sociabilidade, ainda que restritos àqueles que podem usufruí-los, já que os ingressos são cobrados. De forma 
conjunta àquilo que interessa aos grandes produtores agropecuários, somamse também atividades culturais e esportivas que atraem aquela população comum, ou seja, o evento voltado para o consumo produtivo do campo moderno também comporta um consumo consumptivo (que se esgota em si mesmo) (SANTOS, 2008, p.55), de menor importância financeira, mas de maior acesso entre os freqüentadores.

As duplas de música sertaneja, as atividades de rodeio e outras competições com o uso de animais, assim como a realização de sorteios e bingos, aparecem como atrativos na maioria destas exposições agropecuárias $^{7}$. É o momento de festa que a população espera e a semana onde os excessos são permitidos (sobretudo os do consumo). Ocorre, de certo modo, um fenômeno similar ao já observado por R. J. Santos (2008, p.161) nas áreas da produção agrícola moderna no cerrado mineiro, onde a racionalidade da produção e a nova administração do tempo tornam a "festa" mercadoria, ao mesmo tempo em que ela é necessária para a realização (e o enaltecimento) da produção e da produtividade ${ }^{8}$.

O caso das exposições agropecuárias, às vezes tornadas verdadeiros espetáculos de exibição da técnica, para além da sua inegável importância econômica e do seu papel na difusão da informação no campo, também personifica mais um dado da psicosfera que rege os novos espaços agrícolas modernizados, ao mesmo tempo em que fortalece, no lugar, um cotidiano e um modo de vida muito administrados pela racionalidade de tal modernização.

\section{Considerações finais}

Hoje, ciência, técnica e informação constituem os pilares para a realização de uma produção agropecuária guiada por uma racionalidade instrumental, voltada para o mercado e regida por grupos econômicos que, em

\footnotetext{
${ }^{7}$ A edição de 2007 da Expovil realizou bingos que tinham como prêmios dois automóveis zero km, premiação em dinheiro ( $\mathrm{R} \$ 55$ mil) e uma caminhonete Toyota Hilux (sonho de consumo tanto dos produtores agrícolas quanto dos demais habitantes de Vilhena).

8 Tal como fora publicado em uma reportagem de revista em Vilhena, "(...) a exposição [Expovil] transformou-se num fenômeno que tem a capacidade de trazer para a realidade urbana todo o universo rural, com seus costumes, tradições, músicas e danças, pratos e sabores. Não é à toa que a Expovil é uma das festas mais esperadas do ano pelos vilhenenses" (ALERTA NOTICIAS, 2007).
} 
última análise, visam sobretudo manter-se competitivos e tornar cada vez mais viável a sua própria acumulação.

Há que se destacar a capacidade e perspicácia com que os atores hegemônicos criam discursos capazes de fazer proliferar uma psicosfera que legitima a modernização perversa e a atualização hierárquica do território, ao mesmo tempo em que são capazes de criar territorialidades próprias e orientar projetos de uma elite (local e também externa), que disseminam uma alienação territorial (SANTOS, 1994b; RIBEIRO, 2005) capaz de fazer aceitar tais processos, por mais que a riqueza seja desigualmente distribuída e que a sociedade seja desigualmente atendida em suas demandas mais prementes. Assim, a agricultura moderna de exportação realizada no Brasil atual exemplifica a disseminação, nos espaços mais remotos do território, de uma lógica da eficiência e da competitividade, muito orientada por razões externas que viabilizam a acumulação concentrada e corporativa dos recursos, invertendo as suas finalidades.

Até mesmo onde o campo não se apresenta completamente racionalizado ou totalmente instrumentalizado, a idéia de necessidade da informação aparece, e a maioria das feiras e eventos agropecuários, da forma como são realizados, atuam como elemento de difusão da modernidade no campo e, concomitantemente, da sua racionalização. Tais feiras, para além de tudo o que significam em termos de inserção de novos objetos, novas tecnologias e novos capitais no campo, tal como é o caso das principais feiras agropecuárias realizadas em Rondônia, também difundem uma psicosfera modernizadora ${ }^{9}$ que se instala e também "adianta" a inserção dos novos conteúdos modernos no campo. É assim que este campo moderno, intenso em capital, técnica e informação, regido por grandes grupos econômicos muito

\footnotetext{
${ }^{9}$ Como podemos avaliar a partir do caso das feiras agropecuárias no território rondoniense, os agentes que organizam e comandam a agricultura e pecuária modernas no Brasil prestam-se a difundir esta psicosfera modernizadora. Como reconhece Ana Clara Torres Ribeiro, "Essa psicosfera produz a busca social da técnica e a adequação comportamental à interação moderna entre tecnologia e valores sociais. Alguns setores produtivos parecem alimentar, com especial ênfase, os processos culturais de consolidação dessa psicosfera, conformando verdadeiros pólos emissores de valores" (RIBEIRO, 1991, p.48).
} 
ligados a interesses externos, insere em Rondônia um "efeito modernizador"10 (PEREIRA, 2006), e o território, quando transformado por esta agricultura e pecuária modernas, ganha verdadeiro status de espaço "modelo", signo do progresso e do crescimento econômico, realimentando a psicosfera legitimadora da atualização corporativa e hierárquica (SANTOS, 1996).

Se pensadas de modo a atender as demandas de um campo não necessariamente voltado às imposições de um mercado hegemônico voraz, tais feiras e eventos poderiam servir menos como meio de difusão da informação corporativa (seletiva e hierárquica) e mais como difusores de outros tipos de conhecimentos, valorizando experiências alternativas e mais socializantes ${ }^{11}$.

\section{Referências:}

ABRAFRIGO - Associação Brasileira de Frigoríficos. Página na internet (Seção Estatísticas) Disponível em http://www.abrafrigo.com.br , acesso em dezembro de 2008.

ALERTA NOTÍCIAS (Revista). Começa a Expovil 2007. Vilhena se transforma na capital dos negócios em RO. Alerta Notícias. Vilhena, julho de 2007, Ano II, №30, 2007.

CASTILLO, R. A. Exportar alimentos é a saída para o Brasil? O caso do complexo soja. In: ALBUQUERQUE, E. S. (org.) Que país é esse? Pensando o Brasil contemporâneo. São Paulo: Globo, 2005. p.283-307.

COELHO, J. Expojipa vai reunir pecuaristas de todo o país. Folha de Rondônia. Caderno Agrofolha. Ji-paraná, 22/05/2007. Disponível em http://www.folhaderondonia.com.br, acesso em 22/05/2007.

\footnotetext{
10 "Esta renovação do conteúdo material do território confere aos lugares a emergência do que estamos chamando de "efeito modernizador". Este seria todo o conteúdo territorial (objetos e ações) que se impõe como novo, e que, ganhando localmente um caráter de proeminência em relação aos demais, acaba por centralizar toda a atenção e ação dos agentes públicos. Por isso se tratar apenas de uma modernização aparente, porque se dá de forma centralizada e não repercute em ganhos ou melhorias para todos os que habitam o lugar. Tirando proveito político da situação de renovação territorial, e invertendo e distorcendo as atenções da sociedade, o poder público (nas suas diferentes escalas territoriais), apoiado na legitimação aparente dos projetos de modernização e desenvolvimento, se volta para a razão das ações privadas, promovendo desta forma um uso corporativo do território" (PEREIRA, 2006, p.66).

11 É preciso indicar que as práticas de uma agricultura de pequena dimensão, caracterizadas pelo emprego de pouco capital e geralmente pelo pouco acesso às modernidades do período também inicia práticas de difusão de informações através da realização de férias agropecuárias. Em agosto de 2008 , a Fetagro (Federação dos Trabalhadores na Agricultura de Rondônia) realizou a primeira Feira Estadual da Produção (Fepaf), na cidade de Ji-paraná, voltada especificamente para a pequena produção agrícola.
} 
COUTINHO, L. Campo high-tech. Revista Veja. Edição especial n. 30. (Agronegócio). Ano 37, p.24-29. Editora Abril: São Paulo, 2004.

ELIAS, D. Trabalho de campo: notas teórico-metodológicas. Geousp. São Paulo, n.5, p.97-108, 1998.

Edusp, 2003.

Globalização e agricultura: a região de Ribeirão Preto-SP. São Paulo:

- Globalização e fragmentação do espaço agrícola no Brasil. Scripta Nova. Revista Eletrónica de Geografía y Ciencias Sociales. Barcelona, Vol.X, n.218 (03), 2006. Disponível em <http://www.ub.es/geocrit/sn/sn-218-03.htm>, acesso em agosto de 2007.

PEREIRA, M. F. V. O território sob o "Efeito Modernizador": a face perversa do desenvolvimento. Interações. Campo Grande. Vol.8, n.13, p.63-69, 2006. Disponível em <http://www.scielo.br/scielo.php?pid=S151870122006000200007\&script=sci abstract\&tlng=pt>, acesso em outubro de 2006.

RAMOS, S. Sistemas técnicos agrícolas e meio técnico-científico-informacional no Brasil. In: SANTOS, M.; SILVEIRA, M. L. O Brasil: território e sociedade no início do século XXI. Rio de Janeiro: Record, 2001. p.375-387.

RIBEIRO, A. C. T. Matéria e espírito: o poder (des)organizador dos meios de comunicação. In: PIQUET, R.; RIBEIRO, A. C. T. (org.). Brasil, território da desigualdade: descaminhos da modernização. Rio de Janeiro: Jorge Zahar Editor/Fundação Universitária José Bonifácio, 1991, p.44-55.

Território usado e humanismo concreto: o mercado socialmente necessário. In: X ENCONTRO DE GEÓGRAFOS DA AMÉRICA LATINA. São Paulo, março de 2005. Anais... São Paulo: AGB, 2005, p.12458-12470.

SANTOS, M. Técnica, espaço, tempo: Globalização e meio técnico-científico informacional. São Paulo: Hucitec, 1994a.

. O retorno do território. In: SANTOS, M.; SOUZA, M. A. A.; SILVEIRA, M. L. (org.). Território: Globalização e fragmentação. São Paulo: Hucitec,1994b. p.15-20.

A natureza do espaço. Técnica e tempo. Razão e emoção. São Paulo: Hucitec, 1996.

. A urbanização brasileira. São Paulo: Edusp, 2008 (1ª Ed. 1993).

SANTOS, M.; SILVEIRA, M. L. O Brasil: território e sociedade no início do século XXI. Rio de Janeiro: Record, 2001.

SANTOS, R. J. Gaúchos e mineiros do cerrado. Metamorfoses das diferentes temporalidades e lógicas sociais. Uberlândia: Edufu, 2008.

SEAPES (Secretaria de Estado da Agricultura, Produção e do Desenvolvimento Econômico e Social de Rondônia). Boletim informativo agropecuário. Março de 2007. Porto Velho: Gerência de Apoio ao Desenvolvimento AgropecuárioSEAPES, 2007. 